\title{
Integrative literature review of the reported uses of serological tests in leprosy management
}

\author{
Angélica da Conceição Oliveira Coelho Fabri ${ }^{[1],[2]}$, Ana Paula Mendes Carvalho ${ }^{[2]}$, \\ Nayara Figueiredo Vieira ${ }^{[2]}$, Isabela de Caux Bueno ${ }^{[3]}$, Rayssa Nogueira Rodrigues ${ }^{[2]}$, \\ Thayenne Barrozo Mota Monteiro ${ }^{[4]}$, Rodrigo Correa-Oliveira ${ }^{[2],[5],[6],[7],}$ \\ Malcolm S. Duthie ${ }^{[8]}$ and Francisco Carlos Félix Lana ${ }^{[2],[9]}$
}

\begin{abstract}
[1]. Departamento de Enfermagem Básica, Faculdade de Enfermagem, Universidade Federal de Juiz de Fora, Juiz de Fora, Minas Gerais, Brasil. [2]. Programa de Pós-graduação em Enfermagem, Escola de Enfermagem, Universidade Federal de Minas Gerais, Belo Horizonte, Minas Gerais, Brasil. [3]. Escola de Enfermagem, Universidade Federal de Minas Gerais, Belo Horizonte, Minas Gerais, Brasil. [4]. Faculdade de Enfermagem, Universidade Federal de Juiz de Fora, Juiz de Fora, Minas Gerais, Brasil. [5]. Laboratório de Imunologia Celular e Molecular, Centro de Pesquisas René Rachou, Fundação Oswaldo Cruz, Belo Horizonte, Minas Gerais, Brasil. [6]. Laboratório de Imunologia, Núcleo de Pesquisas em Ciências Biológicas, Universidade Federal de Ouro Preto, Ouro Preto, Minas Gerais, Brasil. [7]. Instituto Nacional de Ciência e Tecnologia em Doenças Tropicais, Brasil. [8]. Infectious Disease Research Institute, Seattle WA, USA. [9]. Departamento de Enfermagem Materno Infantil e Saúde Pública, Escola de Enfermagem, Universidade Federal de Minas Gerais, Belo Horizonte, Minas Gerais, Brasil.
\end{abstract}

\begin{abstract}
An integrative literature review was conducted to synthesize available publications regarding the potential use of serological tests in leprosy programs. We searched the databases Literatura Latino-Americana e do Caribe em Ciências da Saúde, Indice Bibliográfico Espanhol em Ciências da Saúde, Acervo da Biblioteca da Organização Pan-Americana da Saúde, Medical Literature Analysis and Retrieval System Online, Hanseniase, National Library of Medicine, Scopus, Ovid, Cinahl, and Web of Science for articles investigating the use of serological tests for antibodies against phenolic glycolipid-I (PGL-I), ML0405, ML2331, leprosy IDRI diagnostic-1 (LID-1), and natural disaccharide octyl-leprosy IDRI diagnostic-1 (NDO-LID). From an initial pool of 3.514 articles, 40 full-length articles fulfilled our inclusion criteria. Based on these papers, we concluded that these antibodies can be used to assist in diagnosing leprosy, detecting neuritis, monitoring therapeutic efficacy, and monitoring household contacts or at-risk populations in leprosy-endemic areas. Thus, available data suggest that serological tests could contribute substantially to leprosy management.
\end{abstract}

Keywords: Serologic tests. Recombinant proteins. Glycolipids. Mycobacterium leprae. Leprosy.

\section{INTRODUCTION}

Leprosy persists as a significant public health issue in many countries, especially those that are socially and economically underdeveloped. In 2013, the World Health Organization (WHO) was notified of 215.656 new cases in 102 countries, with India and Brazil accounting for $58.9 \%$ and $14.4 \%$ of new cases, respectively ${ }^{(1)}$. Among the goals set by the WHO to achieve by end of 2015 was to reduce, by at least $35 \%$ compared to 2010 , new cases among children under 15 years of age, as well new cases with grade 2 disability. These goals were intended to stimulate activities aimed at achieving early diagnosis and providing timely treatment with multidrug therapy, thereby helping to both reduce new cases and minimize transmission of Mycobacterium leprae ${ }^{(2)}$.

Corresponding author: Dra. Angélica da Conceição Oliveira Coelho Fabri. e-mail: angelicacoelho8@gmail.com

Received 7 July 2015

Accepted 16 September 2015
At present, diagnosis is predominantly based on clinical assessment, and therefore depends on recognition of characteristic symptoms. However, investment in new technologies may be necessary to facilitate early diagnosis and to achieve WHO goals. Indeed, while tests such as skin slit smear, Mitsuda test, and histological analyses can accelerate diagnosis, none are $100 \%$ sensitive or specific ${ }^{(3)}$. In addition, a sensitive and specific test to classify leprosy as either paucibacillary or multibacillary is critical in selecting the most appropriate treatment regimen. Thus, the current diagnostic challenge is to identify or develop a point-of-care test that can contribute to or facilitate early diagnosis and classification. Toward this end, immunological tests are being evaluated. Among the most advanced tools in development are tests to detect antibodies against phenolic glycolipid-I (PGL-I), or its di- and trisaccharide analogs NDO and NTP, respectively. Additional diagnostic markers include antibodies against Leprosy IDRI Diagnostic-1 (LID-1), which is a fusion of the ml0405 and ml2331 gene products ${ }^{(4)}$, as well as antibodies against NDO-LID, a conjugate of natural disaccharide octyl (NDO) and LID $^{(5)}$. In this study, we mined the available peer-reviewed scientific literature to assess the value of serological tests in leprosy control programs. 


\section{INTEGRATIVE LITERATURE REVIEW}

In integrative literature review, relevant publications are collected and summarized in a systematic manner, with the intent of consolidating present knowledge of the subject of interest ${ }^{(6)}$. To guide the review, we asked the following question: "How have serology tests for antibodies against PGL-I, ML0405, ML2331, LID-1, and NDO-LID been used to manage leprosy?"

We searched for articles in the databases Literatura LatinoAmericana e do Caribe em Ciências da Saúde (LILACS), National Library of Medicine (PUBMED), Medical Literature Analysis and Retrieval System Online (MEDLINE), Cumulative Index to Nursing and Allied Health Literature (CINAHL), Índice Bibliográfico Espanhol em Ciências da Saúde (IBECS), Acervo da Biblioteca da Organização Pan-Americana da Saúde (PAHO), Hanseníase (HANSEN), SCOPUS, OVID, and Web of Science.

To search in LILACS, IBECS, and PAHO of the Descritores em Ciência da Saúde, the following descriptors were used: "LID1”, “NDO-LID”, "PGL-I”, "PGL-1”, “ML0405”, "ML2331”, "Recombinant Proteins", "Recombinant Fusion Proteins", "Fusion Proteins", "Glycolipids", "Antigens, Bacterial", "Immunoglobulin G", "Immunoglobulin M", "gammaGlobulins", "Immunoglobulin”, “Antibodies, Bacterial”, "IgM", "IgG", "ELISA", "Serologic Tests", "Serodiagnosis", "Agglutination Tests", "Enzyme-Linked Immunosorbent Assay", and "Mycobacterium leprae". The descriptors were used in English, Portuguese, and Spanish, alone or in combination.

In PUBMED, MEDLINE, and CINAHL the following search terms from Medical Subject Headings were used: "Recombinant Proteins", "Recombinant Fusion Proteins", "Glycolipids", “Antigens, Bacterial", "LID-1", "NDO-LID”, "PGL-I", "PGL-1", "Recombinant Proteins", "ML0405", "ML2331", "Immunoglobulin G", "Immunoglobulin M", "Antibodies, Bacterial”, "Gamma Globulin", "IgM", "IgG”, "Antibody", "Serologic Tests", "Agglutination Tests", "Enzyme-Linked Immunosorbent Assay", "ELISA", "ML FLOW", "Mycobacterium leprae", "Leprosy", and "Hansen's Disease".

To be considered for review, papers should have been published between January 2002 and January 2015 in Portuguese, English, or Spanish; should be available as fulltext in electronic format; and should contain at least one of the following terms in the title in any of the three languages: "serology", "seroprevalence", "seropositivity", "subclinical infection", "antibody", “antigen”, “immunological”, "ML Flow", "laboratory test”, "PGL-I”, "PGL-1”, “LID-1”, "NDOLID", "protein", "ML0405", and "ML 2331". In addition, we considered only those articles with level of evidence 1, 2, 3, and 4, as defined in the classification of evidence hierarchical system ${ }^{(7)}$. Article ID, methodological characteristics, methodological rigor, and soundness of results were collected from all candidate articles by four researchers, following an instrument adapted from $\mathrm{Ursi}^{(8)}$. Articles were formally and finally selected by consensus based on suitability and preliminary data from all four researchers. Descriptive analysis was then performed to summarize the main findings of each article with regard to the following themes: "use of serological assays in diagnosis", "surveillance of household contacts and at-risk populations", "value of serological tools in assessing multidrug therapy", and "potential relationship between serum antibodies and $M$. leprae transmission".

\section{ARTICLE SELECTION}

Based on the question "How have serology tests detecting anti-PGL-I, anti-ML0405, anti-ML2331, anti-LID-1 and antiNDO-LID antibodies been used in leprosy?", we identified a total of 3.514 articles, of which 2.554 were duplicated among databases. Duplicates were excluded, along with a further 856 articles excluded based on title, 33 based on abstract, and 31 based on full text, either because the articles did not meet inclusion criteria, or were otherwise unsuitable for the objectives of the review. In the end, 40 articles were considered for final integrative review (Figure 1).

\section{USE OF SEROLOGICAL ASSAYS IN DIAGNOSIS OF LEPROSY}

Testing for anti-PGL-I can help classify leprosy ${ }^{(9)}(10)(11)(12)(13)$ (14)(15) into paucibacillary and multibacillary forms ${ }^{(5)(15)(16)(17)(18)(19)}$ (20) (21) (22) and facilitate differential diagnosis ${ }^{(23)}$ (Table 1). When used in Brazil as an additional tool for classification, a rapid antiPGL-I test called ML Flow reduced the number of cases treated as multibacillary, thus reducing the use of anti-mycobacterial drugs, as well as the amount of case management required. Hence, the test provided a direct benefit during treatment ${ }^{(24)}$.

Testing for antibodies against recombinant ML0405, ML2331, and LID-1 antigens can also assist in diagnosis and classification $^{(5)}$ (17) (25) (26) (Table 1). In particular, antibodies against LID-1 can be used as an immunological marker for leprosy ${ }^{(27)}$, more specifically of the multibacillary presentation ${ }^{(17)}$. Indeed, reports indicate that anti-LID-1 can detect leprosy 6-8 months before clinical symptoms manifest ${ }^{(4)}$. Thus, screening for anti-LID-1 in the general population or in populations at greatest risk of $M$. leprae infection could potentially accelerate treatment, and reduce transmission by effectively reducing the number of individuals with high bacterial load ${ }^{(4)}$.

Tests for antibodies against the NDO-LID conjugate are also essentially tests for antibodies against both PGL-I and LID-1. Thus, such tests can increase the sensitivity and specificity of diagnosis over levels achieved by serological tests for anti-PGL-I only. Indeed, tests based on NDO-LID assist in rapid and consistent detection and monitoring of multibacillary leprosy ${ }^{(5)(28)(29)}$ (Table 1).

Antibodies in the sera may be measured by techniques such as

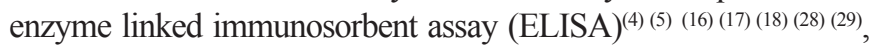
and lateral flow tests such as ML Flow ${ }^{(9)(10)(11)(12)(13)(16)(18)(19)(20)(24) ~}$ and NDO-LID ${ }^{\circledR}$ rapid test ${ }^{(28)}$. Indeed, laboratory-based ELISA has been used to analyze seroreactivity against PGL-I ${ }^{(4)(5)(17)}$, LID- $^{(4)(5)}$ ${ }^{(17)}$, ML0405, ML2331 ${ }^{(4)(17)}$, and NDO-LID ${ }^{(5)(29)}$. On the other hand, ML Flow is a simple, fast ${ }^{(9)}$, and reliable tool to detect anti-PGL-I ${ }^{(10)}$ using NTP as antigen, a semi-synthetic trisaccharide analog of PGL-I that is chemically linked to either bovine or human serum albumin ${ }^{(11)}$. Finally, the NDO-LID ${ }^{\circledR}$ rapid test is used to detect antibodies against both the LID-1 chimeric fusion protein and NDO, a disaccharide analog of PGL-I ${ }^{(28)}$. Importantly, ML Flow and NDO-LID ${ }^{\circledR}$ 


\section{Selection of Studies}

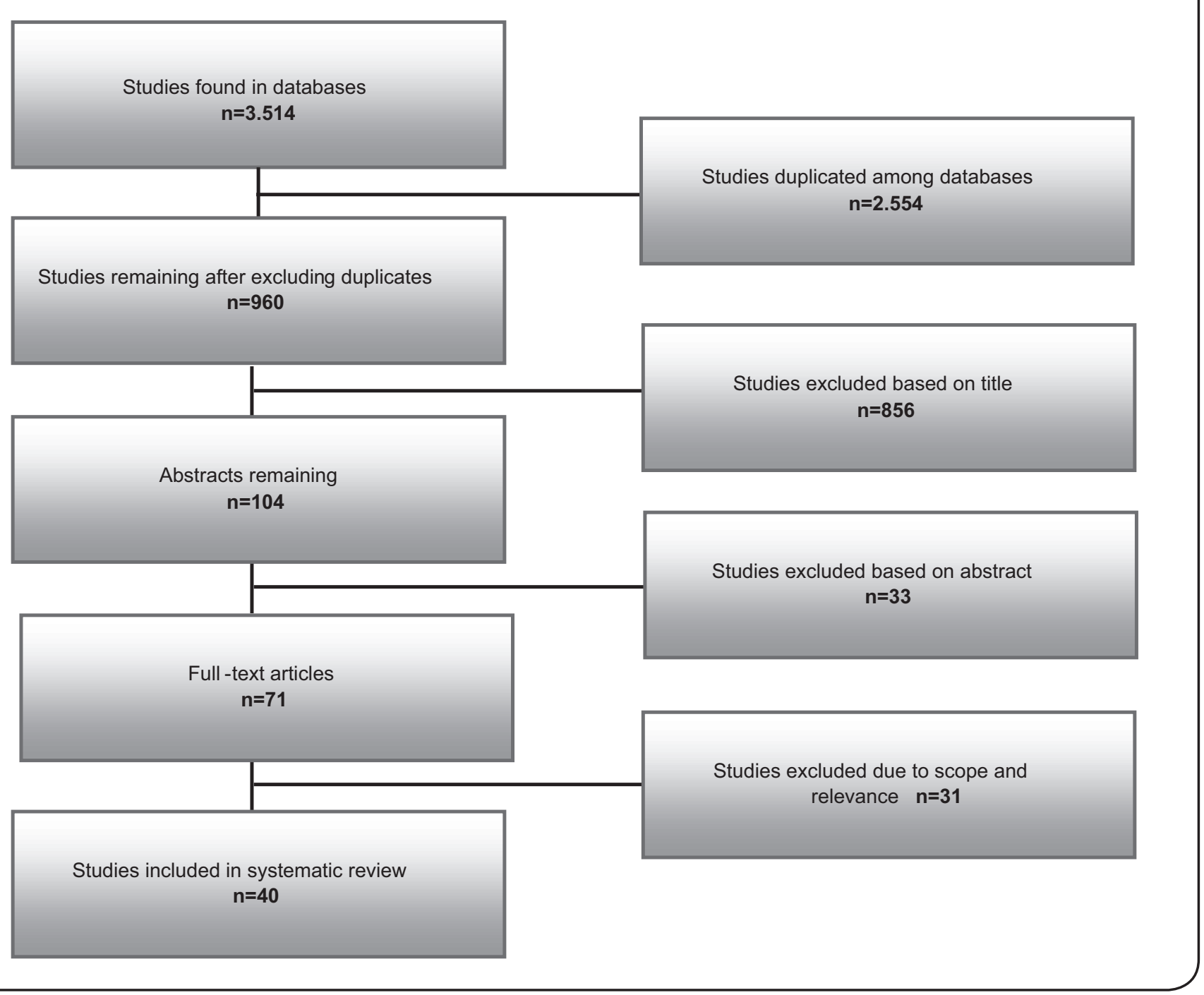

FIGURE 1 - Selection of studies for integrative review.

rapid test are simple serological tests that can readily be used by healthcare professionals providing primary care, and, unlike ELISA, are not dependent upon laboratory analysis.

\section{SURVEILLANCE OF HOUSEHOLD CONTACTS AND AT-RISK POPULATIONS}

Measurement of immunoglobulin M (IgM) antibodies against PGL-I may be useful to assess exposure to $M$. leprae. As anti-PGL-I is a marker for those at a higher risk of developing leprosy, screening could be used for early diagnosis in household contacts ${ }^{(12)(21)(30)(31)}$, and for detection of individuals with subclinical, asymptomatic $M$. leprae infection ${ }^{(18)(21)}$ (32) (Table 2). Indeed, household contacts who test positive for anti-PGL-I are at increased risk of developing either form of leprosy(33) (34), especially in households with an index case of multibacillary leprosy ${ }^{(21)}$. In particular, the estimated risk of developing multibacillary leprosy is 34.4 times higher when antibodies against PGL-I are detected ${ }^{(33)}$. Similarly, evaluation of $\mathrm{IgM}$ and immunoglobulin $\mathrm{G}(\mathrm{IgG})$ antibodies against the NDO-LID conjugate allows detection of a significant number of $M$. leprae-infected individuals in early stages of disease development ${ }^{(29)}$. Further, accurate measurement of antibody titers may also be useful, because increased titers of antiPGL-I (NDO-BSA) and anti-LID-1 could potentially identify household contacts that require careful monitoring or clinical examination $^{(35)}$ (Table 2). On balance, the data suggest that simultaneous assessment of multiple antibodies to detect possible $M$. leprae infection may identify contacts at greatest risk of becoming ill $^{(36)}$.

People at risk of developing leprosy should be carefully monitored $^{(34)(37)}$ (Table 2) or, to prevent new cases, subjected to intervention strategies such as post-exposure prophylaxis ${ }^{(21)(37)}$. 
TABLE 1 - Use of serological tests as an auxiliary tool to diagnose leprosy.

\begin{tabular}{llr}
\hline Antigen & Major findings/comments & References \\
\hline PGL-I native and/or mimetic & Helps detect early-stage leprosy & $39,10,12,13,14,15,24$ \\
& Helps classify patients correctly & $5,15,16,17,18,19,20,21,22,24,44$ \\
& Assists in differentiating between MB and PB forms & 23 \\
& Assists in differential diagnosis & 11 \\
& Assists in identifying patients with high bacterial load & 25,43 \\
ML0405 & Helps diagnose MB leprosy & 25 \\
ML2331 & Improves performance of anti-PGL-I tests & $5,17,26$ \\
LID-1 & Assists in diagnosis and classification & 27 \\
& Assists in diagnosis & 17,25 \\
& Assists in diagnosis, specifically of MB leprosy & 4 \\
NDO-LID & Assists in detecting early-stage leprosy & 25 \\
& Improves performance of anti-PGL-I tests & 5,28 \\
& Assists in rapid and consistent detection of MB leprosy & 29 \\
\hline
\end{tabular}

PGL-I: phenolic glycolipid-I; ML: Mycobacterium leprae; LID-1: leprosy IDRI diagnostic-1; NDO-LID: natural disaccharide octyl-leprosy IDRI diagnostic-1; MB: multibacillary; PB: paucibacillary.

TABLE 2 - Use of serological tests in surveillance programs.

\begin{tabular}{|c|c|c|}
\hline Antigen & Major findings/comments & References \\
\hline \multirow[t]{6}{*}{ PGL-I native and/or mimetic } & Used to evaluate exposure to antigen & 30 \\
\hline & Assists in identifying individuals with subclinical infection & $18,21,32$ \\
\hline & Can identify contacts at high risk of developing leprosy & $11,14,21,31,33,34,36$ \\
\hline & Can identify broad groups most at risk of becoming ill & 37 \\
\hline & Assists in identifying school-age children with higher risk of developing leprosy & 38 \\
\hline & Assists in estimating potential of $M$. leprae transmission & 37 \\
\hline ML0405 & Enhances PGL-I tests in identifying contacts at greater risk of developing leprosy & 40 \\
\hline \multicolumn{3}{|l|}{ ML2331 } \\
\hline \multirow[t]{2}{*}{ NDO-LID } & Allows detection of early-stage infection & 29 \\
\hline & Can be used to monitor suspected cases of $M$. leprae infection & 29 \\
\hline
\end{tabular}

PGL-I: phenolic glycolipid-I; ML: Mycobacterium leprae; LID-1: leprosy IDRI diagnostic-1; NDO-LID: natural disaccharide octyl-leprosy IDRI diagnostic-1; M.: Mycobacterim. 
Indeed, household contacts with subclinical M. leprae infection could actively transmit $M$. leprae to susceptible individuals ${ }^{(21)}$, and are thus a concern. Detection of antibodies against PGL-I can identify school-age children with increased risk of developing leprosy ${ }^{(38)}$ (Table 2). Indeed, seroepidemiology studies of antiPGL-I and the prevalence of previously undetected leprosy among household contacts and school children suggest that active $M$. leprae infection and sustained circulation persist in many regions. Notably, clinical and serological surveys among students in hyperendemic areas help identify patients at an earlier stage of disease than otherwise would be achieved. Fortunately, diagnoses are typically provided before physical disabilities develop, while treatment and education help prevent further infections in the community ${ }^{(39)}$.

In addition, detection of antibodies against recombinantly expressed M. leprae proteins enhances PGL-I-based identification of household contacts at greater risk of developing leprosy ${ }^{(40)}$ (Table 2). Indeed, the LID-1 antigen may be used as a screening tool ${ }^{(41)}$, while evaluation of antibodies against NDO-LID can improve surveillance, facilitate referral to an expert ${ }^{(29)}$, and help develop new interventions and treatments.

We note that in hyperendemic areas, leprosy control activities should extend beyond household contacts and into the general population, which might also be considered at high risk $^{(31)}$. The possibility and feasibility of carrying out large-scale screening campaigns to detect antibodies against PGL-I, LID-1, and NDO-LID should therefore be investigated as a means to identify M. leprae-infected individuals ${ }^{(5)}$. Regular and sustained monitoring of suspected cases is also suggested ${ }^{(29)}$.

Since successive evaluation of antibodies may contribute to early diagnosis, rapid tests based on PGL-I, LID-1, and NDO-LID antigens should be incorporated into primary health care services in order to detect household contacts and other individuals at risk of becoming sick. It also appears prudent to extend these assays into clinical surveys in schools and the general population in leprosy endemic areas.

\section{SEROLOGICAL TOOLS IN EVALUATING MULTIDRUG THERAPY}

As noted, serological tests can help classify leprosy patients, and thus help determine the most appropriate multidrug therapy regimen ${ }^{(3)(10)(18)(42)}$ (Table 3). As serological evaluations correlate well with bacterial index ${ }^{(3)(42)(43)}$, these tests can inform treatmentrelated decisions when bacilloscopy is not available ${ }^{(13)(44)}$. Indeed, serological assays could reduce the risk of undertreatment and supplant bacilloscopy, a more invasive and risky procedures ${ }^{(13)}$. When used as basis for selecting the multidrug therapy regimen, serological anti-PGL-I tests reduce nerve damage and associated physical disabilities ${ }^{(18)}$. Corollarily, as patients with impaired nerve function typically have high levels of anti-PGL-I IgM and $\mathrm{IgG}$, serological evaluation may also assist in identifying individuals with nerve damage (Table 3). The association between high antibody titers and nerve damage highlights the need to detect and treat serologically positive individuals as soon as possible ${ }^{(45)}$.

Serum antibodies can also be a useful measure of the effectiveness of treatments ${ }^{(4)(26)(27)}$ (Table 3). Indeed, antibody titers decline after multidrug therapy ${ }^{(4)(18)(27)(29)}$, with IgG against LID-1 diminishing faster than IgM against PGL-I or NDO$\mathrm{BSA}^{(26)}$. Hence, serological assays could be used to indirectly assess bacterial load after completion of treatment, and may detect persistent bacterial multiplication, which could result in reactions or relapse $\mathrm{e}^{(9)}$. Re-emergence or increase of $\operatorname{IgM}$ and $\operatorname{IgG}$ titers can also indicate reinfection, and persistent seropositivity may indicate high risk of symptoms appearing even years later ${ }^{(26)}$ (Table 3). Further, measurement of anti-PGL-I in patients with reactions after treatment helps to identify individuals that should undergo further treatment, prevention, or monitoring. Leprosy control personnel should thus evaluate the possibility of using serological assays in patients who are at risk for developing reactions after multidrug therapy, because these tools can support new strategies for prevention and disease $\operatorname{control}^{(9)}$.

\section{SERUM ANTIBODIES AS MEASURES OF MYCOBACTERIUM LEPRAE TRANSMISSION POTENTIAL}

Detection of serum anti-PGL-I enhances diagnostic accuracy, guides treatment, and thereby reduces transmission of $M$. leprae from patients ${ }^{(10)(36)}$. Anti-PGL-I screening to identify, monitor, and treat contacts or other people most at risk of developing leprosy may also reduce $M$. leprae transmission ${ }^{(12)}$. Indeed, individuals living in proximity to patients with anti-PGL-I

TABLE 3 - Use of serological tests in therapy and neuritis.

\begin{tabular}{llr}
\hline Antigens & Major finding/comments & \multicolumn{1}{c}{ References } \\
\hline PGL-I native and/or mimetic & Assists in selecting the most appropriate multidrug therapy & Can be considered as marker of re-infection and indicate long-term high risk of leprosy \\
& Allows evaluation of multidrug therapy 18, 24, 42 \\
& Enables assessment of bacterial load after treatment \\
& Helps detect nerve damage \\
& Allows evaluation of multidrug therapy \\
ML0405 & Indicates long-term high risk of leprosy \\
ML2331 & Can be considered as markers of re-infection \\
LID-1 &
\end{tabular}

PGL-I: phenolic glycolipid-I; ML: Mycobacterium leprae; LID-1: leprosy IDRI diagnostic-1. 
have increased likelihood of themselves producing antibodies to $M$. leprae. Thus, assessing serological status with simple tests such as ML flow can provide a more reliable assessment of transmission potential, as well as broaden the definition of contact $^{(37)}$ (Table 2). Detection of antibodies against LID-1, or against both PGL-I and LID-1, has similar benefits ${ }^{(5)(28)}$. In the end, simple serological tools could enable monitoring at a greater frequency than can be achieved with clinical exams, and this is an important consideration for the success of any leprosy control program.

In summary, the published literature indicates that serological tests for antibodies against PGL-I, ML0405, and ML2331 (in the form of conjugated antigens LID-1 or NDO-LID) can assist in the diagnosis and classification of leprosy. Furthermore, assessment of these antibodies may also help determine the choice of multidrug therapy, as well as monitor its effectiveness. Moreover, anti-PGL-I testing may assist in identifying individuals with nerve damage, as well as those more likely to be affected by reaction episodes after bacteriological clearance.

Most people infected with M. leprae do not develop clinical symptoms. Therefore, a major challenge for leprosy control and elimination is to identify individuals who will become ill, and to take steps to prevent illness ${ }^{(38)}$. Fortunately, detection of antibodies against LID-1 and NDO-LID can facilitate early diagnosis of multibacillary leprosy. Indeed, serological tests for antibodies against PGL-I, ML0405, ML2331, LID-1, and NDO-LID can contribute to surveillance of both household contacts and the general population.

\section{ACKNOWLEDGMENTS}

We thank the Coordenação de Aperfeiçoamento de Pessoal de Nivel Superior (CAPES), Brazil for the Senior Research Fellowship to RCO and Conselho Nacional de Desenvolvimento Cientifico e Tecnológico (CNPq), Brazil for the PhD Scholarship Sandwich (SWE) to ACOCF. We thank the members of the research group Núcleo de Estudos e Pesquisas em Hanseníase (NEPHANS) for their participation in data discussion. We also thank American Leprosy Mission who provided funding to the Infectious Disease Research Institute (IDRI).

\section{CONFLICT OF INTEREST}

The authors declare that there is no conflict of interest.

\section{REFERENCES}

1. World Health Organization. Weekly epidemiological record; v. 89 , n. 36 , p. $389-400 ; 2014$.

2. World Health Organization. "Enhanced global strategy for further reducing the disease burden due to leprosy (2011-2015): operational guidelines (updated)"; 2009.

3. Contin LA, Alves CJM, Fogagnolo L, Nassif PW, Barreto JA, Lauris JRP, et al. Use of the ML-Flow test as a tool in classifying and treating leprosy. An Bras Dermatol 2011; 86:91-95.
4. Duthie MS, Goto W, Ireton GC, Reece ST, Cardoso LP, Martelli CMT, Stefani MMA, et al. Use of protein antigens for early serological diagnosis of leprosy. Clin Vaccine Immunol 2007; 14:1400-1408.

5. Duthie MS, Raychaudhuri R, Tutterrow YL, Misquith A, Bowman $\mathrm{J}$, Casey A, et al. A rapid ELISA for the diagnosis of MB leprosy based on complementary detection of antibodies against a novel protein-glycolipid conjugate. Diagn Microbiol Infect Dis 2014; 79:233-239.

6. Ursi ES, Galvão CM. Prevenção de lesões de pele no perioperatório: revisão integrativa da literatura. Rev Latino-am Enfermagem 2006; 14:124-131.

7. Stetler CB, Morsi D, Rucki S, Broughton S, Corrigan B, Fitzgerald $\mathrm{J}$, et al. Utilization-focused integrative reviews in a nursing service. Appl Nurs Res 1998; 11:195-206.

8. Ursi ES. Prevenção de lesões de pele no perioperatório: revisão integrativa da literatura. 2005. 130 p. (dissertação). Escola de Enfermagem de Ribeirão Preto. Universidade de São Paulo, Ribeirão Preto; 2005.

9. Brito MFM, Ximenes RAA, Gallo MEN, Bührer-Sékula S. Association between leprosy reactions after treatment and bacterial load evaluated using anti PGL-I serology and bacilloscopy. Rev Soc Bras Med Trop 2008; 41:67-72.

10. Grossi MAF, Leboeuf MAA, Andrade ARC, Bührer-Sékula S, Antunes CMF. Risk factors for ML flow seropositivity in leprosy patients. Rev Soc Bras Med Trop 2008; 41:39-44.

11. Moura RS, Penna GO, Fujiwara T, Pontes MA, Cruz R, Gonçalves HS, et al. Evaluation of a rapid serological test for leprosy classification using human serum albumin as the antigen Carrier. J Immunol Methods 2014; 412:35-41.

12. Bührer-Sékula S, Smits HL, Gussenhoven GC, Leeuwen JV, Amador S, Fujiwara T, et al. Simple and fast lateral flow test for classification of leprosy patients and identification of contacts with high risk of developing leprosy. J Clin Microbiol 2003; 41:19911995.

13. Bührer-Sékula S, Visschedijk J, Grossi MAF, Dhakal kP, Namadi AU, Klatser PR, et al. The ML Flow test as a point of care test for leprosy control programmes: potential effects on classification of leprosy patients. Lepr Rev 2007; 78:70-79.

14. Ferreira MAA, Antunes CMDF. Factors associated with ML Flow test seropositivity in leprosy patients and household contacts under the age of 18. Rev Soc Bras Med Trop 2008; 41:60-66.

15. Lyon S, Lyon AC, Da Silva RC, Grossi MA, Lyon SH, BührerSékula S, et al. A comparison of ML Flow serology and slit skin smears to assess the bacterial load in newly diagnosed leprosy patients in Brazil. Lepr Rev 2008; 79:162-170.

16. Silva RC, Lyon S, Lyon AC, Grossi MAF, Lyon SH, BührerSékulac S, et al. Correlation between ELISA and ML Flow assays applied to 60 Brazilian patients affected by leprosy. Trans R Soc Trop Med Hyg 2010; 104:546-550.

17. Duthie MS, Ireton GC, Kanaujia GV, Goto W, Liang H, Bhatia A, et al. Selection of Antigens and Development of Prototype Tests for Point-of-Care Leprosy Diagnosis. Clin Vaccine Immunol 2008; 15:1590-1597.

18. Lobato J, Costa MP, Reis EDM, Alves MAG, Spancer AJS, Brennan P, et al. Comparison of three immunological tests for leprosy diagnosis and detection of subclinical infection. Lepr Rev 2011; 82:1-14.

19. Ferreira IN, Ferreira ILCSN, Evangelista MDSN, Alvarez RRA. The use of ML Flow test in school children diagnosed with leprosy 
in the district of Paracatu, Minas Gerais. Rev Soc Bras Med Trop 2008; 41:77-80.

20. Stefani MMDA, Grassi AB, Sampaio LH, Sousa ALOMD, Costa MB, Scheelbeek P, et al. Comparison of two rapid tests for antiphenolic glycolipid-I serology in Brazil and Nepal. Mem Inst Oswaldo Cruz 2012; 107:124-131.

21. Araújo S, Lobato J, Reis EDM, Souza DOB, Gonçalves MA, Costa $\mathrm{AV}$, et al. Unveiling healthy carriers and subclinical infections among household contacts of leprosy patients who play potential roles in the disease chain of transmission. Mem Inst Oswaldo Cruz 2012; 107:55-59.

22. Teixeira AC, Cruvinel DL, Roma FR, Luppino LF, Resende LHP, Sousa T, et al. Evaluation of the agreement between clinical and laboratorial exams in the diagnosis of leprosy. Rev Soc Bras Med Trop 2008; 41:48-55.

23. Amador MDPSC, Cunha MHCMD, Cruz CAVD. Análise imunodiagnóstica do teste Anti-PGL-1 na diferenciação entre Hanseníase Clínica e Reação hansênica pós-cura. Cad Saude Colet 2007; 15: 357-368.

24. Grossi MADF, Leboeuf MAA, Andrade ARCD, Lyon S, Antunes CMDF, Sékula SB. The influence of ML Flow test in leprosy classification. Rev Soc Bras Med Trop 2008; 41:34-38.

25. Hungria EM, Oliveira RM, Souza AL, Costa MB, Souza VN, Silva EA, et al. Seroreactivity to new Mycobacterium leprae protein antigens in different leprosy-endemic regions in Brazil. Mem Inst Oswaldo Cruz 2012; 107:104-111.

26. Duthie MS, Hay MN, Rada EM, Convit J, Ito L, Oyafuso LK, et al. Specific IgG antibody responses may be used to monitor leprosy treatment efficacy and as recurrence prognostic markers. Eur J Clin Microbiol Infect Dis 2011; 30:1257-1265.

27. Rada E, Duthie MS, Reed SG, Aranzazu N, Convit J. Serologic follow-up of $\mathrm{IgG}$ responses against recombinant mycobacterial proteins ML0405, ML2331 and LID-1 in a leprosy hyperendemic area in Venezuela. Mem Inst Oswaldo Cruz 2012; 107:90-94.

28. Cardoso LPV, Dias RF, Freitas AA, Hungria EM, Oliveira RM, Collovati M, et al. Development of a quantitative rapid diagnostic test for multibacillary leprosy using smart phone technology. BMC Infect Dis 2013; 3:497-507.

29. Duthie MS, Balagon MF, Maghanoy A, Orcullo FM, Cang M, Dias RF, Collovati M, et al. Rapid quantitative serological test for detection of infection with Mycobacterium leprae, the causative agent of leprosy. J Clin Microbiol 2014; 52:613-619.

30. Bazan-Furini R, Motta ACF, Simão JCL, Tarquínio DC, Marques Jr W, Barbosa MHN, et al. Early detection of leprosy by examination of household contacts, determination of serum anti PGL-1 antibodes and cosanguinity. Mem Inst Oswaldo Cruz 2011; 106:536-540.

31. Brasil MTLRF, Oliveira LR, Rímoli NS, Cavallari SF, Gonçalves OS, Lessa ZL, et al. Anti PGL-1 serology and the risk of leprosy in a highly endemic area in the State of São Paulo, Brazil: four-year follow-up. Rev Bras Epidemiol 2003; 6:262-271.

32. Kampirapap K. Assessment of subclinical leprosy infection through the measurement of PGL-1 antibody levels inresidents of a former leprosy colony in Thailand. Lepr Rev 2008; 79:315-319.
33. Douglas JT, Cellona RV, Fajardo Jr TT, Abalos RM, Balagon MV, Klatser PR. Prospective study of serological conversion as a risk factor for development of leprosy among household contacts. Clin Diagn Lab Immunol 2004; 11:897-900.

34. Düppre NC, Camacho LA, Sales AM, Illarramendi X, Nery JA, Sampaio EP, et al. Impact of PGL-I seropositivity on the protective effect of BCG vaccination among leprosy contacts: a cohort study. PLoS Negl Trop Dis 2012; 6:e1711.

35. Qiong-Hua P, Zhong-Yi Z, Jun Y, Yan W, Lian-Chao Y, Huan-Ying L, et al. Clinical study - early revelation of leprosy in china by sequential antibody analyses with lid-1 and PGL-I. J Trop Med $2013 ; 352689$.

36. Cardona-Castro NC, Alzate JCB, Hernández RM. Survey to identify Mycobacterium leprae-infected household contacts of patients from prevalent regions of leprosy in Colombia. Mem Inst Oswaldo Cruz 2008; 103:332-336.

37. Bakker MI, Hatta M, Kwenang A, Faber WR, van Beers SM, Klatser PR, et al. Population survey to determine risk factors for Mycobacterium leprae transmission and infection. Int J Epidemiol 2004; 33:1329-1336.

38. Barreto JG, Guimarães LDS, Leão MGN, Ferreira DVG, Lima RADA, Salgado CG. Anti-PGL-I seroepidemiology in leprosy cases: household contacts and school children from a hyperendemic municipality of the Brazilian Amazon. Lepr Rev 2011; 82: 358-370.

39. Barreto JG, Guimarães LS, Frade MAC, Rosa PS, Salgado CG. High rates of undiagnosed leprosy and subclinical infection amongst school children in the Amazon Region. Mem Inst Oswaldo Cruz 2012; 107:60-67.

40. Spencer JS, Duthie MS, Geluk A, Balagon MF, Kim HJ, Wheat $\mathrm{WH}$, et al. Identification of serological biomarkers of infection, disease progression and treatment efficacy for leprosy. Mem Inst Oswaldo Cruz 2012; 107:79-89.

41. Souza MM, M Netto E, Nakatani M, Duthie MS. Utility of recombinant proteins LID-1 and PADL in screening for Mycobacterium leprae infection and leprosy. Trans R Soc Trop Med Hyg 2014; 108:495-501.

42. Lyon S, Silva RCD, Lyon AC, Grossi MADF, Lyon SH, Azevedo MDL, et al. Association of the ML Flow serologic test to slit skin smear. Rev Soc Bras Med Trop 2008; 41:23-26.

43. Limeira OM, Gomes CM, Morais OO, Cesetti MV, Alvarez RR. Active search for leprosy cases in midwestern Brazil: A serological evaluation of asymptomatic household contacts before and after prophylaxis with bacillus Calmette-Guérin. Rev Inst Med Trop Sao Paulo 2013; 55:173-177.

44. Bührer-Sékula S, Illarramendi X, Teles RB, Penna ML, Nery JA, Sales AM, et al. The additional benefit of the ML Flow test to classify leprosy patients. Acta Trop 2009; 111:172-176.

45. Jadhav R, Suneetha L, Kamble R, Shinde V, Devi K, Chaduvula MV, et al. Analysis of Antibody and Cytokine Markers for Leprosy Nerve Damage and Reactions in the INFIR Cohort in India. PLoS Neg1 Trop Dis 2011; 5:e977. 